\title{
Quantification of Pulmonary Perfusion with Free-Breathing Dynamic Contrast-Enhanced MRI - A Pilot Study in Healthy Volunteers
}

\section{Quantifizierung der Lungenperfusion mit dynamischer kontrastmittel- verstärkter MRT unter freier Atmung - Eine Pilotstudie in gesunden Probanden}

Authors

Affiliations
D. Maxien', M. Ingrisch², F. G. Meinel', M. Reiser², O. Dietrich², K. Nikolaou'

Institute for Clinical Radiology, Ludwig-Maximilians-University Hospital Munich

Josef Lissner Laboratory for Biomedical Imaging, Institute for Clinical Radiology, Ludwig-Maximilians-University Hospital Munich
Key words

- thorax

MR diffusion/perfusion

- MR functional imaging

- MR imaging

eingereicht 8.3.2013

akzeptiert 17.6.2013

Bibliography

DOI http://dx.doi.org/

10.1055/s-0033-1350128

Published online: 24.7.2013

Fortschr Röntgenstr 2013; 185:

1175-1181 @ Georg Thieme

Verlag KG Stuttgart · New York .

ISSN 1438-9029

\section{Correspondence \\ Dr. Daniel Maxien}

Institute for Clinical Radiology, Ludwig-Maximilians-University Hospital Munich LMU

Nußbaumstr. 20

80336 Munich

Germany

Tel.: ++ 49/08 95/1609201

Fax: ++49/08 95/1609202

daniel.maxien@med.uni-

muenchen.de

\section{Zusammenfassung}

$\nabla$

Ziel: Die Untersuchung der Lungenperfusion mittels dynamischer kontrastverstärkter MRT (DynKM-MRT) ist nur eingeschränkt in der klinischen Routine möglich, da die Untersuchung üblicherweise nur mit angehaltenem Atem erfolgt. In der aktuellen Studie wurde eine Akquisitionstechnik zur Bestimmung quantitativer Perfusionsparameter während freier Atmung untersucht.

Material und Methoden: 10 gesunde männliche Probanden wurden einer DynKM-MRT an einem 1,5-T-Scanner unterzogen. Jeder Proband wurde zweimal untersucht; einmal mit der Vorgabe den Atem in halber Exspiration anzuhalten und einmal während flacher freier Atmung. Das Lungenparenchym wurde automatisch segmentiert. Der pulmonale Plasmafluss (PPF) und das pulmonale Plasmavolumen (PPV) wurden mit einem 1-Kompartiment-Modell pixelweise bestimmt.

Ergebnisse: Alle Untersuchungen waren von diagnostischer Bildqualität. Die gemessen durchschnittlichen Werte des PPV waren signifikant geringer in der Atemanhalttechnik als unter freier Atmung. ([10,2 $\pm 2,8] \mathrm{ml} / 100 \mathrm{ml}$ vs. [12,7 \pm $3,9] \mathrm{ml} / 100 \mathrm{ml}) ; \mathrm{p}<0,05)$. Auch zwischen den beiden PPF-Messungen wurde ein signifikanter Unterschied beobachtet (durchschnittlicher PPF [206.2 \pm 104.0$] \mathrm{ml} / 100 \mathrm{ml} / \mathrm{min}$ beim Atemanhalt vs. $[240.6 \pm 114.0] \mathrm{ml} / 100 \mathrm{ml} / \mathrm{min}$ unter freier Atmung; $\mathrm{p}<0,05$ ).

Schlussfolgerung: Die Bestimmung von quantitativen Perfusionsparametern durch eine DynKM-MRT während freier Atmung in gesunden Probanden scheint möglich zu sein. Die vorgestellte Quantifizierungstechnik leidet im Vergleich zu den Messungen mit angehaltenem Atem nicht unter den verstärkten Atembewegungen. Das erhöhte PPV und der erhöhte PPF unter freier Atmung decken sich mit Ergebnissen aus vorherigen Studien über den Einfluss der Atemtiefe auf die Perfusionsparameter. Zusam-

\section{Abstract \\ $\nabla$}

Purpose: The assessment of pulmonary perfusion using dynamic contrast-enhanced (DCE) MRI is still limited in the clinical routine due to the necessity of breath holding. An acquisition technique for the quantitative assessment of pulmonary perfusion in free breathing was investigated in our study.

Materials and Methods: 10 healthy male volunteers underwent pulmonary DCE-MRI on a $1.5 \mathrm{~T}$ scanner. Each volunteer was examined twice: (a) in breath-hold half expiration and (b) during shallow free breathing. The pulmonary parenchyma was segmented automatically. The pulmonary plasma flow (PPF) and pulmonary plasma volume (PPV) were determined pixel-wise using a onecompartment model.

Results: All examinations were of diagnostic image quality. The measured mean values of the PPV were significantly lower in the breath-hold technique than during free breathing ((10.2 $\pm 2.8) \mathrm{ml} / 100 \mathrm{ml}$ vs. $(12.7 \pm 3.9) \mathrm{ml} / 100 \mathrm{ml}) ; \mathrm{p}<0.05)$. A significant difference was also observed between both PPF measurements (mean PPF (206.2 \pm 104.0 ) $\mathrm{ml} / 100 \mathrm{ml} / \mathrm{min}$ in breath-hold technique vs. $(240.6 \pm 114.0) \mathrm{ml} / 100 \mathrm{ml} / \mathrm{min}$ during free breathing; $\mathrm{p}<0.05$ ).

Conclusion: Free-breathing DCE-MRI appears to be suitable for the quantitative assessment of the pulmonary perfusion in healthy volunteers. The proposed segmentation and quantification approach does not suffer from the increased motion, as compared to the breath-holding measurement. The increased PPV and PPF during free breathing are in accordance with the results of previous studies concerning breathing influence on perfusion parameters. Overall, free-breathing DCE-MRI may be a promising technique for the assessment of pulmonary perfusion in various pathologies. 
menfassend könnte die DynKM-MRT unter freier Atmung eine vielversprechende Technik für die Bestimmung der Lungenperfusion bei einer Vielzahl von Krankheiten sein.

\section{Citation Format:}

- Maxien D, Ingrisch M, Meinel F et al. Quantification of Pulmonary Perfusion with Free-Breathing Dynamic Contrast-Enhanced MRI - A Pilot Study in Healthy Volunteers. Fortschr Röntgenstr 2013; 185: 1175-1181

\section{Introduction}

$\nabla$

Magnetic resonance imaging (MRI) of the chest is becoming increasingly important in all age groups and various diseases due to continuous advancements in this imaging technique [1-3]. Nevertheless, imaging of the lungs is still a challenge for MRI. MRI of the lungs suffers from low signal intensities and severe susceptibility artifacts, caused by the heterogeneous structure of the lung, which consists mainly of air-filled microscopic alveoli with a large interface between air spaces and tissue or blood $[4,5]$. Hence, morphological lung MRI is still inferior if compared with computed tomography (CT).

However, quantitative functional lung imaging with repeated measurements is well feasible, due to the absence of ionizing radiation [6]. Dynamic contrast-enhanced (DCE) MRI is a well-established technique to assess pulmonary perfusion [7, 8]. A bolus of contrast agent (CA) is administered rapidly during a DCE-MRI examination of the lungs and subsequently, the spatial and temporal distribution of the CA in the lung tissue is monitored using an appropriate fast imaging sequence [6]. The time-resolved CA concentrations in each voxel can be approximated from the measured signal intensities and further analyzed by means of tracer-kinetic theory, to derive quantitative perfusion parameters such as pulmonary plasma flow (PPF, $\mathrm{ml} / 100 \mathrm{ml} / \mathrm{min}$ ) or pulmonary plasma volume (PPV, $\mathrm{ml} / 100 \mathrm{ml}$ ) [9-13]. Nevertheless, the breathing-related motion is still an issue during the quantitative assessment of pulmonary perfusion using DCE-MRI. Hence, measurements are commonly conducted during breath hold, with typical breath-hold times between 20 and 30 seconds. However, this has to be considered as a severe technical limitation, since especially patients suffering from lung diseases are frequently unable to hold their breath long enough for the assessment of pulmonary perfusion.

To circumvent this limitation, it would be ideal to conduct measurements during free breathing. The use of free-breathing acquisition techniques for pulmonary perfusion imaging has been reported $[14,15]$, but these techniques are technically challenging and/or suffer from low temporal resolution. Hence, a robust, technically simple, free-breathing acquisition technique with a high temporal resolution would be desirable. Therefore, the aim of this study was to investigate whether the quantification of pulmonary perfusion is feasible using data acquired during shallow free breathing without any further dedicated post-processing, by simply ignoring the breathing-related motion for perfusion quantification. Additionally, quantitative parameters as derived from free-breathing acquisitions were intra-individually compared to perfusion parameters derived from data acquired with a conventional breath-holding technique.

\section{Materials and Methods}

$\nabla$

\section{Volunteers and study design}

The institutional ethics committee approved the study protocol of this volunteer study. The inclusion criteria were male gender, health (especially concerning chest disease), and non-smoking. Overall, ten healthy, male volunteers (mean age $30.4 \pm 4.6$ years, range 25 - 39 years; mean BMI $26.8 \pm 5.7 \mathrm{~kg} / \mathrm{m}^{2}$, range $20-35 \mathrm{~kg} /$ $\mathrm{m}^{2}$ ) without any symptoms or previous medical history of chest disease were enrolled.

Each volunteer underwent two DCE-MRI acquisitions, one breath-hold and one free-breathing acquisition, separated by a 20-minute break. The volunteers were randomized in two groups $(n=5)$. In the first group, the free-breathing measurement was performed prior to the measurement in breath hold. In the second group, the measurements were conducted in reverse order. All volunteers were given oral instructions as to how to breathe and underwent training to adjust the depth of inspiration/expiration during quiet breathing and breath holding in half-expiration prior to the contrast-enhanced examinations. The training was visually controlled and took about 5 minutes.

\section{MR acquisition}

All examinations were performed on a 1.5-T whole-body MRI system (Magnetom Aera, Siemens Healthcare, Erlangen, Germany) after optimization of the scan protocol and the contrast dosage in a single healthy volunteer. A 16-channel spine array coil and an 18-channel body matrix coil were used for signal reception.

A $3 \mathrm{D}$ spoiled gradient-echo sequence was used for the dynamic acquisitions. The $3 \mathrm{D}$ volume was oriented coronal with phase-encoding from left to right. 36 slices were acquired every $1.31 \mathrm{sec}-$ onds. Detailed sequence parameters are provided in $\bullet$ Table 1.

For both free-breathing and breath-hold measurements, a body weight (BW)-adapted amount of $0.1 \mathrm{mmol} / \mathrm{kg}$ BW of contrast agent (Gd-DO3-A-butrol, Gadovist ${ }^{\circledR}$, Bayer Healthcare, Berlin, Germany) was injected with a flow rate of $3 \mathrm{ml} / \mathrm{s}$, followed by a saline flush of $25 \mathrm{ml}$, injected with the same flow rate. The acquisition was started simultaneously with the contrast injection. A total of 40 volumes were acquired for the breath-hold measurements, amounting to a total acquisition time of 53 seconds. Since the free-breathing measurement has inherently less temporal restrictions, a total of 110 frames was acquired in 146 seconds, with an otherwise unmodified sequence. For the breath-hold measurement, the volunteers were instructed to hold their breath as long as possible in half-expiration, and continue with quiet

Table 1 Detailed sequence parameters.

Tab. 1 Detaillierte Sequenzparameter.

\begin{tabular}{|c|c|c|}
\hline & breath hold & free breathing \\
\hline TE/TR & \multicolumn{2}{|c|}{$0.9 \mathrm{~ms} / 2.0 \mathrm{~ms}$} \\
\hline matrix size & \multicolumn{2}{|c|}{$128 \times 128 \times 36$} \\
\hline spatial resolution & \multicolumn{2}{|c|}{$3 \times 3 \times 4 \mathrm{~mm}^{3}$} \\
\hline temporal resolution & \multicolumn{2}{|c|}{$1.3 \mathrm{~s}$} \\
\hline TWIST: pA/pB & \multicolumn{2}{|c|}{$0.21 / 0.26$} \\
\hline bandwidth & \multicolumn{2}{|c|}{$1115 \mathrm{~Hz} /$ pixel } \\
\hline total acquisition time & $53 s$ & $146 s$ \\
\hline acquired volumes & 40 & 110 \\
\hline
\end{tabular}


breathing, if necessary. For the free-breathing measurement, volunteers were instructed to breathe quietly throughout the entire measurement.

\section{Post-processing: Segmentation and calculation of parameter maps}

The acquired data was transferred to a separate workstation and analyzed with an in-house written post-processing solution (PMI 0.4 [16], written in IDL). An arterial region was defined in the pulmonary artery and was used to calculate parameter maps of the cross-correlation and the normalized area under the curve (nAUC), as described previously [10]. These maps were used for the segmentation of the lung parenchyma, i.e., all pixels with nAUC values between 0.05 and 0.5 and cross-correlation values between 0.3 and 0.9 were defined as lung parenchyma and included in further analysis. This segmentation process removes the central vessels from the evaluation mask and also the basal regions of the lungs with diaphragm displacement ( $\bullet$ Fig. 1 ). The volume of this segmented region was recorded.

A one-compartment tracer-kinetic model was fitted to each pixel curve in the previously defined regions for the quantification of pulmonary perfusion, yielding parameter maps of PPF and PPV $[10,17]$.

\section{Statistical analysis}

Statistical analysis was performed in R (www.r-project.org). The median values derived from the aforementioned calculated parameter maps were further evaluated. The non-parametric Mann-Whitney U-test was used to compare the outcome of measurements in breath hold with measurements during free breathing. The local significance level is set to 0.05. An adjustment to multiplicity is not performed. Therefore, an overall significance level is not determined and cannot be calculated. The presented findings may be used to generate new hypotheses.

\section{Results}

$\nabla$

All measurements were completed successfully. No adverse events were observed. All data and acquisitions were of diagnostic image quality. No parameter maps, neither from free-breathing nor from breath-holding measurements, suffered from major artifacts which visually hampered a qualitative assessment of the lung perfusion ( Fig. 1).

The mean respiration rate during free breathing was $15.9 \pm 3.9$ / min (range: $10 / \mathrm{min}-22 / \mathrm{min}$ ).

The measured median values of the PPV were increased during the free-breathing acquisition in 9 of 10 volunteers. Furthermore, the calculated median values of the PPF were increased in the free-breathing examinations in 8 of 10 volunteers. The detailed values of the measured PPF and PPV in all volunteers are given in

\section{- Fig. 3, Table 2.}

The averaged median values of the PPV were $(10.2 \pm 2.8) \mathrm{ml} / 100 \mathrm{ml}$ (range: $7.5 \mathrm{ml} / 100 \mathrm{ml}-16.3 \mathrm{ml} / 100 \mathrm{ml}$ ) in the breath-hold technique and $(12.7 \pm 3.9) \mathrm{ml} / 100 \mathrm{ml}$ (range: $7.7 \mathrm{ml} / 100 \mathrm{ml}-18.5 \mathrm{ml} /$ $100 \mathrm{ml}$ ) during free breathing. The mean PPV in the breath-hold technique was significantly lower compared to the PPV during free breathing $(p<0.05)$.

Accordingly, the mean values of the PPF were $(206.2 \pm 104.0) \mathrm{ml} /$ $100 \mathrm{ml} / \mathrm{min}$ (range: $112.3 \mathrm{ml} / 100 \mathrm{ml} / \mathrm{min}-453.9 \mathrm{ml} / 100 \mathrm{ml} / \mathrm{min}$ )

Tab. 2 Measured median values of pulmonary plasma flow (PPF) and pulmonary plasma volume (PPV) during breath hold (BH) and free breathing.

Tab. 2 Gemessene Medianwerte des pulmonalen Plasmaflusses (PPF) und des pulmonalen Plasmavolumens unter Atemanhalt $(\mathrm{BH})$ beziehungsweise unter freier Atmung (FB).

\begin{tabular}{|c|c|c|c|c|}
\hline volunteer & $\begin{array}{l}\text { PPF (BH) } \\
(\mathrm{ml} / 100 \mathrm{ml} / \\
\mathrm{min})\end{array}$ & $\begin{array}{l}\text { PPF (FB) } \\
(\mathrm{ml} / 100 \mathrm{ml} / \\
\min )\end{array}$ & $\begin{array}{l}\text { PPV (BH) } \\
(\mathrm{ml} / 100 \mathrm{ml})\end{array}$ & $\begin{array}{l}\text { PPV (FB) } \\
(\mathrm{ml} / 100 \mathrm{ml})\end{array}$ \\
\hline 1 & 208.3 & 267.3 & 12.4 & 15.3 \\
\hline 2 & 172.9 & 311.6 & 7.9 & 14.6 \\
\hline 3 & 166.6 & 136.4 & 9.6 & 10.7 \\
\hline 4 & 301.4 & 317.3 & 16.3 & 18.5 \\
\hline 5 & 116.1 & 144.6 & 7.8 & 8.8 \\
\hline 6 & 122.3 & 124.1 & 7.5 & 7.7 \\
\hline 7 & 112.3 & 188.9 & 7.5 & 10.9 \\
\hline 8 & 453.9 & 491.6 & 12.0 & 17.2 \\
\hline 9 & 190.8 & 164.8 & 11.1 & 8.5 \\
\hline 10 & 216.9 & 259.5 & 10.0 & 15.0 \\
\hline mean & 206.2 & 240.6 & 10.2 & 12.7 \\
\hline SD & 104.0 & 114.0 & 2.8 & 3.9 \\
\hline $\mathrm{p}$-value & 0.049 & & 0.019 & \\
\hline
\end{tabular}
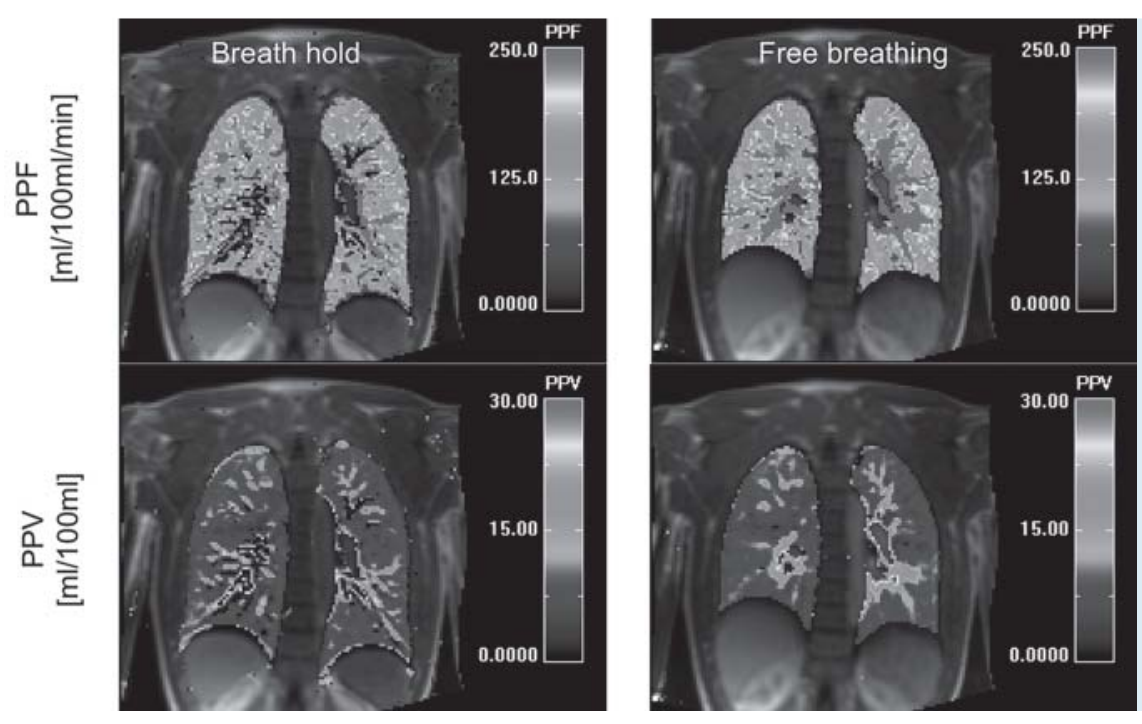

Fig. 1 The figure shows one slice of representative parameter maps of the pulmonary plasma flow (PPF) and the pulmonary plasma volume (PPV) in one volunteer, demonstrating the feasibility of freebreathing DCE-MRI without major artifacts. Note the overall increased lung volume during breath hold.

Abb. 1 Die Abbildung zeigt eine Schicht einer repräsentativen Parameterkarte des pulmonalen Plasmaflusses bzw. des pulmonalen Plasmavolumens eines Probanden und demonstriert die Möglichkeit einer KM-MRT unter freier Atmung ohne größere Artefakte. Zu beachten ist auch das insgesamt erhöhte Lungenvolumen bei angehaltenem Atem. 

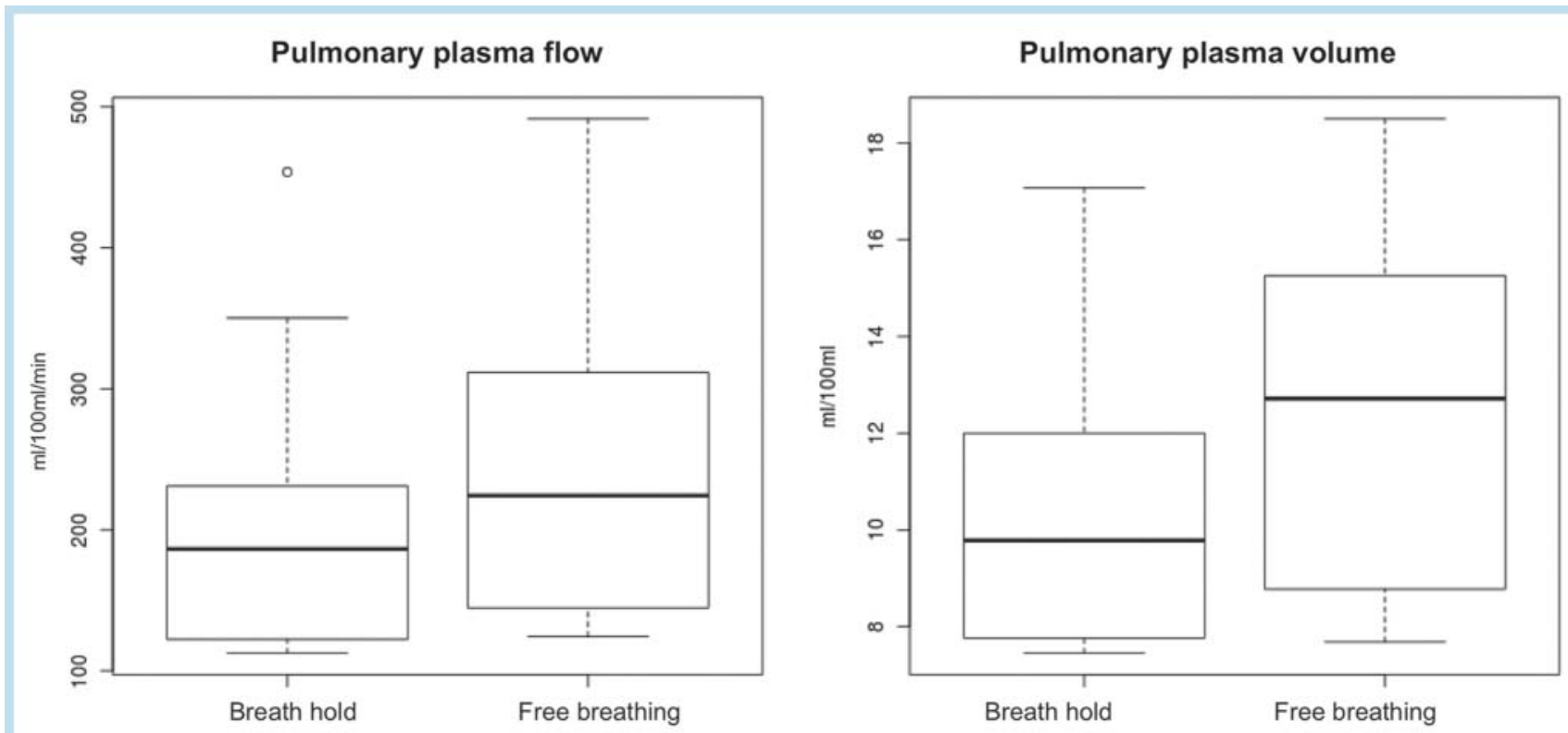

Fig. 2 Box plots of PPF and PPV values in all volunteers.

Abb. 2 Boxplots der PPF- und PPV-Werte aller Probanden.

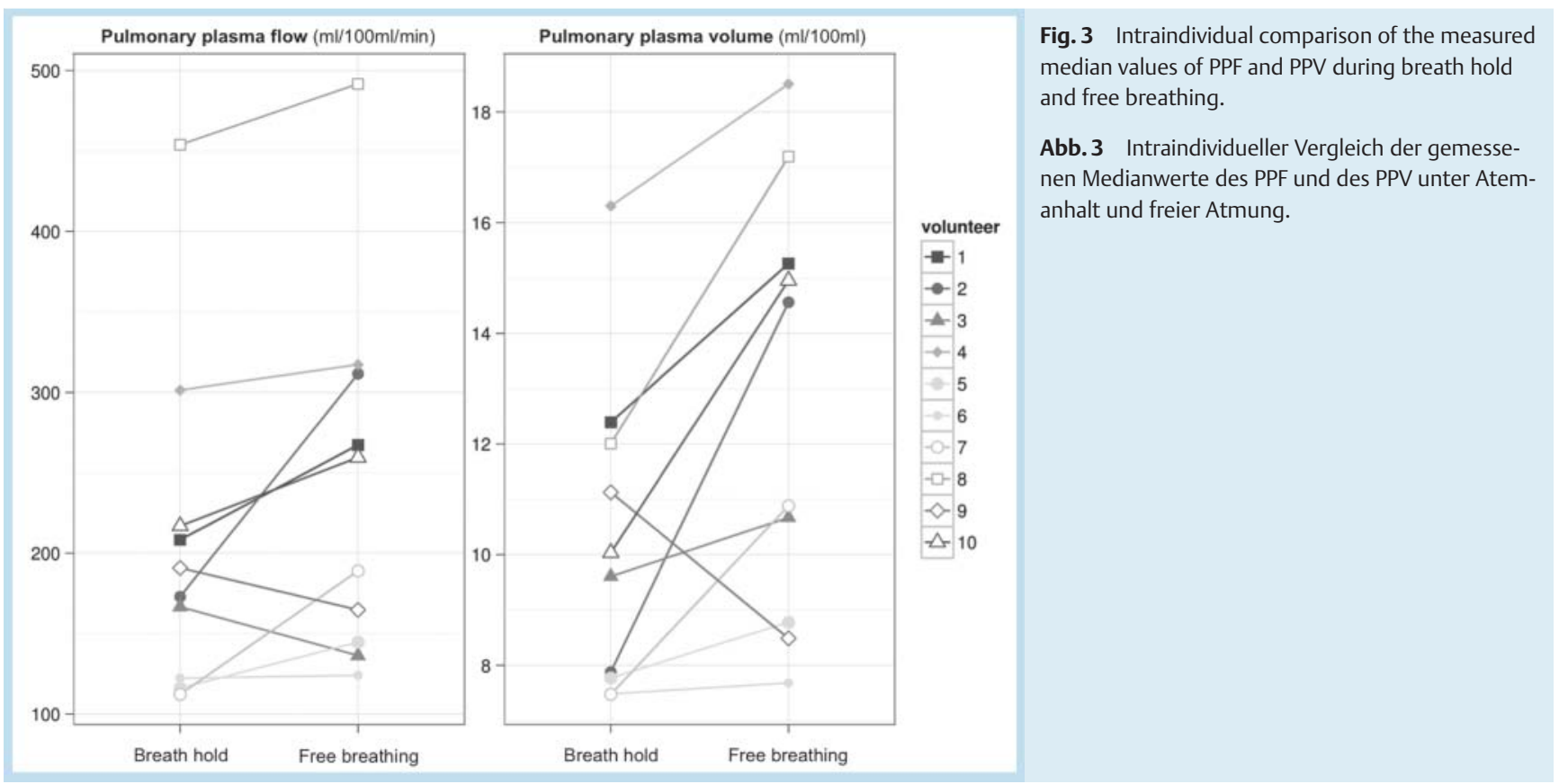

in the breath-hold technique and $(240.6 \pm 114.0) \mathrm{ml} / 100 \mathrm{ml} / \mathrm{min}$ (range: $124.1 \mathrm{ml} / 100 \mathrm{ml} / \mathrm{min}$ - $491.6 \mathrm{ml} / 100 \mathrm{ml} / \mathrm{min}$ ) during free breathing. This observed difference also reached the significance level $(p<0.05)$ ( $\bullet$ Fig. 2, $\diamond$ Table 2$)$.

The mean lung volumes were $3.2 \pm 0.71$ during breath hold and $2.3 \pm 0.61$ during free breathing ( $\bullet$ Fig. 4 ).

\section{Discussion}

In the past, breathing-related motion has been considered a severe limitation for quantitative pulmonary perfusion MRI. In areas of excessive motion, motion-induced signal changes were expected to mask and conceal the signal changes caused by the CA distribution, affecting a quantitative assessment of perfusion parameters.

Instructing patients to hold their breath during a pulmonary DCE-MRI examination seems to be a simple and straightforward strategy to solve this problem. However, breath hold itself may represent a severe limitation, forcing the implementation of protocols with short acquisition times to enable patients to hold their breath during the whole examination. Depending on the type and duration of a perfusion examination, not even healthy volunteers may be able to hold their breath long enough to finish 


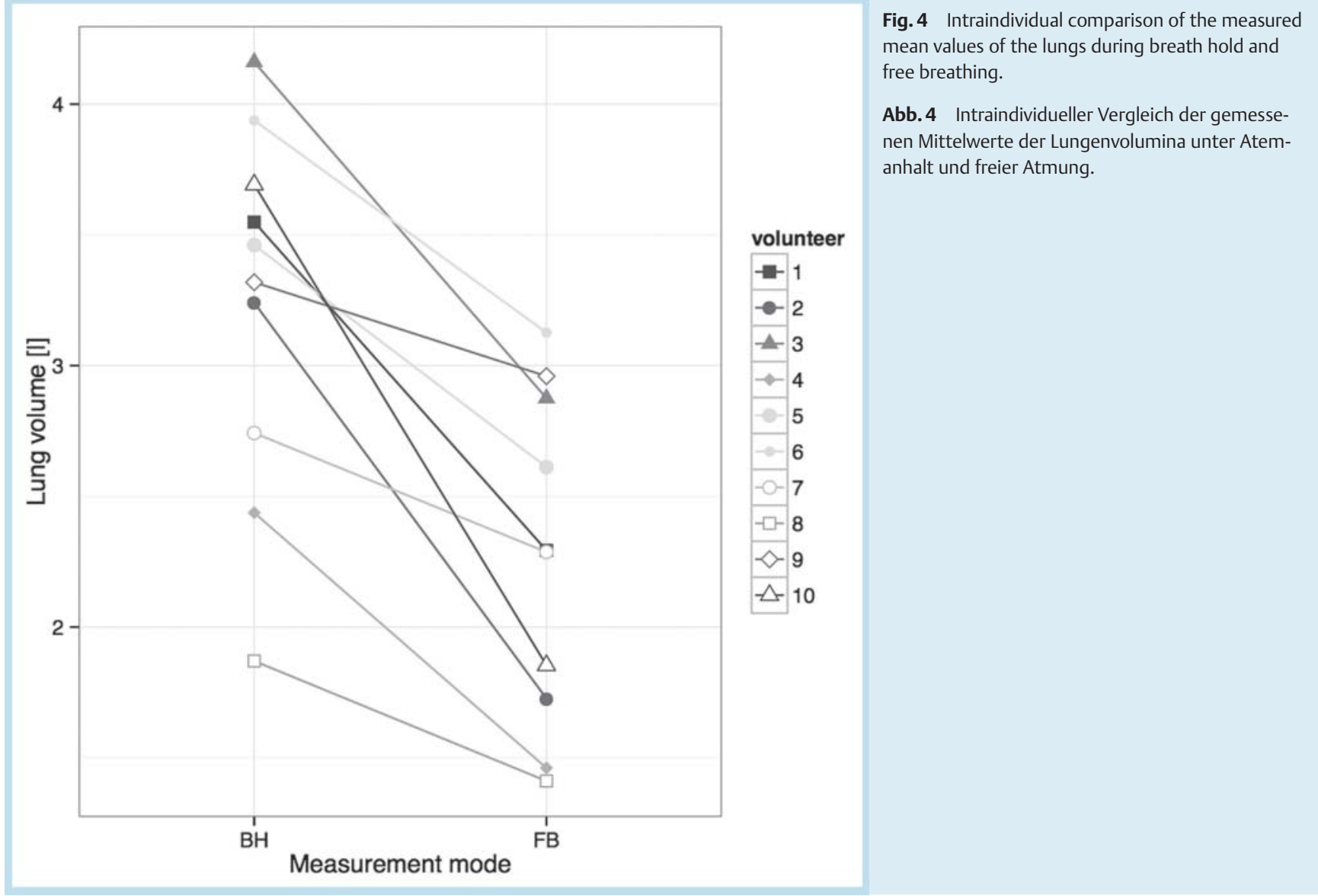

an examination in breath hold, let alone patients suffering from pulmonary pathologies. Additionally, relatively deep gasping associated with distinctive diaphragm motion often follows the breath-hold period, potentially influencing and hindering a quantitative perfusion assessment.

Hence, dynamic contrast-enhanced acquisition during free breathing would be highly desirable. There are several strategies to establish such an acquisition $[14,15]$. The commonly used triggered acquisitions (using a respiratory belt) or acquisitions with additional retrospective gating of diaphragmatic motion share one problem: Only images where the diaphragm is at the same position are used for the perfusion analysis. Images with the diaphragm at a position that differs from the accepted range of diaphragm positions are either not recorded (in case of a triggered acquisition) or discarded after the examination (in case of retrospective gating). This leads to a significantly reduced temporal resolution, even with modern fast $3 \mathrm{D}$ GRE sequences, and may cause prolonged overall acquisition times. Moreover, it might happen that the rapid signal changes that occur during the examination, in particular during the first pass of the contrast agent, are missed. A recently introduced and more elaborate way of conducting lung-perfusion measurements during free breathing is the implementation of a so-called "elastic registration". With this technique motion-correction is achieved by aligning, via pair-wise non-rigid registration, a reference image to the remaining images of the sequence [15]. A special algorithm estimates the deformation that maximizes the local cross-correlation between the reference image and the uncorrected image [15]. However, this approach necessitates the addition of complex calculations to the post-processing of the MRI data. This is technically challenging, in part because such a post-processing tool is currently not commercially available. Furthermore, using this technique, it is difficult to estimate whether a signal change in a voxel is due to motion or triggered by the CA distribution.

Overall, a technically less challenging free-breathing technique with high temporal resolution is desirable. We acquired perfusion data during shallow free breathing and simply ignored the breathing motion in our study. This seemed to be a promising way due to several precautions. The quiet breathing produces only mild breathing-related motion, typically limited to the region of the diaphragm or inferior lung segments. Therefore, the implemented cross-correlation-based approach used for tissue segmentation excluded those regions close to the diaphragm that suffered greatly from breathing-related motion ( $\bullet$ Fig. 1 ). None of the maps derived from free-breathing examinations suffered from major artifacts. A wide inter-individual range of pulmonary perfusion parameters is well known and our measured quantitative values of the free-breathing examination are within this previously reported range ( $\bullet$ Fig. 3) $[10-12,18]$. However, we also observed significant intra-individual differences of the quantitative perfusion parameters when comparing the data derived from free-breathing acquisitions with results from breathhold examinations. In fact, both the PPF and PPV were significantly higher when calculated from the free-breathing examinations. In the first instance, this might look like a systematic bias, but actually, this observation is in accordance with previous studies $[11,18,19]$. We found out that in all volunteers the average lung volumes were significantly higher during the breathhold measurements ( Fig. 1, 4). This is important to know because the degree of lung inflation has a direct effect on the blood 
vessels within the thorax. Increased inflation causes increased compression of the alveolar blood vessels [18]. This results in increased pulmonary vascular resistance with reduced pulmonary perfusion [18]. Possibly, this effect is largely negligible since its influence should be much lower in our measurements in half expiration than in full inspiration. A probably more important factor is that the quantitative perfusion parameters are defined to be normalized to volume (PPF: $\mathrm{ml} / 100 \mathrm{ml} / \mathrm{min}$; PPV: $\mathrm{ml} / 100 \mathrm{ml}$ ). If the lung volume is decreased during free breathing, the normalized volume contains less air and a higher fraction of tissue and blood. Hence, e. g. the PPV increases automatically if in total, the same amount of blood is transported through the lungs, because the same amount of blood (and contrast agent) is distributed within an overall smaller volume. This explains the observed decrease of the PPF and PPV in the breath-hold examinations.

The contrast dosage is also a parameter that may influence the observed quantitative perfusion values. The chosen dosage in our study is relatively high. It is known that the quantitative perfusion assessment is hampered if the concentration of the contrast agent is outside the linearity range in the arterial inflow function (AIF) [12]. The used dosage exceeded the often-proposed dosage, which is approximately $0.07 \mathrm{mmol} / \mathrm{kg}$ BW. Therefore, a saturation shown by a flattening of the AIF curve seems to be possible. Nevertheless, we observed no such flattening of our measured AIF curves. Moreover, the measured quantitative perfusion parameters were within a physiological range. In fact, there is an explanation for these observations. The possible saturation depends on the sequence parameters and on the concentration of the contrast agent within the blood. The concentration is determined by multiple factors. Obviously, the flow is one important parameter for the concentration. The used flow of $3 \mathrm{ml} / \mathrm{s}$ is relatively low. Moreover, the amount of venous blood returning to the heart in which the contrast agent is dissolved is crucial. This parameter is hard to estimate but it is likely that it is relatively high in young healthy male volunteers due to an assumed good blood circulation and an overall relatively high blood volume. This might be an explanation as to why we found no hint of such a saturation bias. In addition, even if there was a bias due to the contrast dosage, it would have affected the assessed freebreathing measurements as well as the gold standard breathhold measurements. Hence, the conclusions concerning feasibility should not be hampered due to the study design.

The free-breathing approach enabled us to significantly increase the total acquisition duration ( $\bullet$ Table 2 ). This prolonged acquisition time might not be necessary to quantitatively assess perfusion values in healthy lung tissue, but might be useful for a quantitative assessment of perfusion in diseased lung tissue with an altered CA distribution, e.g. in tumors.

Nevertheless, there are some noteworthy limitations to our study. The overall cohort size of our study is relatively small and included healthy volunteers only. The results may differ in a larger group of individuals, or in patients with lung diseases. For example, it is possible that patients might not be able to breathe as regularly and shallowly as healthy volunteers, potentially inducing increased motion within the thorax.

The volunteers were told how to breathe and were visually controlled during breathing training prior to the examinations. We had no mechanical or other control mechanism to quantify the depth of inspiration and expiration. Although we observed no conspicuities concerning the depth of breath and the respiration rate, there may be variations that have a possible influence on the measured perfusion values, potentially limiting the clinical value of this technique.

No further assessment of the lung function (e.g. by spirometry) was conducted in our healthy volunteers. Hence, the informative value of the lung volumes ( $\bullet$ Fig. 4) is limited, especially concerning the observed differences between breath hold and free breathing.

In addition, we assessed no follow-up examination to test the reproducibility. Therefore, it is not possible to estimate whether the measured quantitative parameters are reliable in an intra-individual time course. Further studies are necessary to answer this question.

Furthermore, the time interval between the breath-hold and the free-breathing examination was rather short (20 minutes), thus, the CA from the first injection may not have been entirely eliminated. However, the perfusion calculation is based on an individual baseline calculation. Hence, the remaining CA after the first examination should not have affected the results of the second examination [11].

In conclusion, DCE-MRI during shallow free breathing without any special post-processing to reduce breathing motion is feasible for the quantitative assessment of pulmonary perfusion in healthy volunteers. The observed increased PPV and PPF during free breathing are in accordance with the results of previous studies concerning the influence of the inspiration levels on quantitative perfusion parameters. Overall, in the clinical routine, free-breathing DCE-MRI might be a promising, more robust and more comfortable acquisition technique for the assessment of pulmonary perfusion, especially in patients suffering from pulmonary pathologies, limiting the usage of breath-holding acquisition strategies.

\section{Acknowledgement}

$\nabla$

This study was supported by the Deutsche Forschungsgemeinschaft (DFG grants DI 1413/2 - 3 and NI 707/1 - 3).

Furthermore, the assistance of Michele Cosimo Picciolo during the examinations is gratefully acknowledged.

\section{References}

1 Achenbach S, Barkhausen J, Beer $M$ et al. Consensus recommendations of the German Radiology Society (DRG), the German Cardiac Society (DGK) and the German Society for Pediatric Cardiology (DGPK) on the use of cardiac imaging with computed tomography and magnetic resonance imaging. Fortschr Röntgenstr Apr 2012; 184 (4): 345 - 368

2 Groth $M$, Henes FO, Bannas $P$ et al. Intraindividual comparison of contrast-enhanced MRI and unenhanced SSFP sequences of stenotic and non-stenotic pulmonary artery diameters. Fortschr Röntgenstr Jan 2011; 183: 47-53

3 Ley-Zaporozhan J, Ley S, Sommerburg O et al. Clinical application of MRI in children for the assessment of pulmonary diseases. Fortschr Röntgenstr 2009; 181: 419-432

4 Hopkins SR, Prisk GK. Lung perfusion measured using magnetic resonance imaging: New tools for physiological insights into the pulmonary circulation. J Magn Reson Imaging 2010; 32: 1287-1301

5 Thieme SF, Dietrich O, Maxien D et al. Oxygen-enhanced MRI of the lungs: intraindividual comparison between 1.5 and 3 tesla. Fortschr Röntgenstr Apr 2011; 183: 358 - 364

6 Ley S, Ley-Zaporozhan J. Pulmonary perfusion imaging using MRI: clinical application. Insights into imaging 2012; 3: 61 -71

7 Henzler T, Schmid-Bindert G, Schoenberg SO et al. Diffusion and perfusion MRI of the lung and mediastinum. Eur J Radiol 2010; 76: 329-336 
8 Ohno Y, Hatabu H, Murase K et al. Primary pulmonary hypertension: 3D dynamic perfusion MRI for quantitative analysis of regional pulmonary perfusion. Am J Roentgenol Am J Roentgenol 2007; 188: 48 - 56

9 Attenberger UI, Ingrisch $M$, Dietrich $O$ et al. Time-resolved 3D pulmonary perfusion MRI: comparison of different k-space acquisition strategies at 1.5 and $3 \mathrm{~T}$. Invest Radiol 2009; 44: 525-531

10 Ingrisch $M$, Dietrich $O$, Attenberger UI et al. Quantitative pulmonary perfusion magnetic resonance imaging: influence of temporal resolution and signal-to-noise ratio. Invest Radiol 2010; 45: 7-14

11 Ley-Zaporozhan J, Molinari F, Risse F et al. Repeatability and reproducibility of quantitative whole-lung perfusion magnetic resonance imaging. J Thorac Imaging 2011; 26: 230-239

12 Nikolaou K, Schoenberg SO, Brix G et al. Quantification of pulmonary blood flow and volume in healthy volunteers by dynamic contrast-enhanced magnetic resonance imaging using a parallel imaging technique. Invest Radiol 2004; 39: 537-545

13 Plathow C, Ley S, Zaporozhan J et al. Assessment of reproducibility and stability of different breath-hold maneuvres by dynamic MRI: comparison between healthy adults and patients with pulmonary hypertension. Eur Radiol 2006; 16: 173-179
14 Hintze C, Stemmer A, Bock $M$ et al. A hybrid breath hold and continued respiration-triggered technique for time-resolved 3D MRI perfusion studies in lung cancer. Fortschr Röntgenstr 2010; 182: 45-52

15 Bauman G, Puderbach $M$, Deimling $M$ et al. Non-contrast-enhanced perfusion and ventilation assessment of the human lung by means of fourier decomposition in proton MRI. Magn Reson Med 2009; 62: $656-664$

16 Sourbron S, Biffar A, Ingrisch $M$ et al. PMI: platform for research in medical imaging. Magn Reson Mater Phy 2009; 22: 539

17 Sourbron S. Technical aspects of MR perfusion. Eur J Radiol 2010; 76: $304-313$

18 Fink C, Ley S, Risse F et al. Effect of inspiratory and expiratory breathhold on pulmonary perfusion: assessment by pulmonary perfusion magnetic resonance imaging. Invest Radiol 2005; 40: 72 -79

19 Ley S, Fink C, Puderbach M et al. MRI Measurement of the hemodynamics of the pulmonary and systemic arterial circulation: influence of breathing maneuvers. Am J Roentgenol Am J Roentgenol 2006; 187: $439-444$

Erratum to „Maxien D, Ingrisch M, Meinel FG, Reiser M, Dietrich O, Nikolaou K. Quantification of Pulmonary Perfusion with Free-Breathing Dynamic Contrast-Enhanced MRI - A Pilot Study in Healthy Volunteers. Fortschr Röntgenstr 2013: DOI 10.1055/s-0033-1350128“

The middle initial of one of the authors was omitted in the original publication. It was corrected to Meinel FG. 